\title{
Verification and Control of Solving Pseudo-Real Problems Related to the Systems of Equations
}

\author{
Le Van Tien ${ }^{1}$, Duong Huu Tong ${ }^{2, *}$, Nguyen Thi Tu Vy ${ }^{3}$ \\ ${ }^{1}$ National College of Education, Ho Chi Minh City, Vietnam \\ ${ }^{2}$ School of Education, Can Tho University, Can Tho City, Vietnam \\ ${ }^{3}$ Thanh Da High School, Ho Chi Minh City, Vietnam
}

Received May 4, 2020 ; Revised June 9, 2020; Accepted June 15, 2020

Copyright@2020 by authors, all rights reserved. Authors agree that this article remains permanently open access under the terms of the Creative Commons Attribution License 4.0 International License

\begin{abstract}
In general, people tend to examine and reevaluate the suitability of the results to end the activity. In particular, it is essential to check and to review operations in the process of solving a mathematical problem, since it enables the evaluation of the reasonability of the data presented by the given problem. This study aimed to detect and enhance the control and verification activities of students as they solved pseudo-real problems associated with the systems of equations with two unknowns in high schools. The empirical sample consisted of 91 10th grade students, and the instrument used was made up of four pseudo-real problems. The teaching process covered the individual as well as the group stages of the work, especially the participants' discussion stages. To clarify the verification and control process of the students when solving the given problems, the researchers analyzed the data collected qualitatively. It turned out that the students stopped verifying the results and managed to resolve all the problems with the initial conditions. The answers did not appear to be realistic in all the students' worksheets in the process. Nevertheless, in the course of such learning, the students became more aware of the fact that they never before had to verify and control the results of the problems. Moreover, empirical findings produced various vital implications for teachers and students and recommendations.
\end{abstract}

Keywords Control, Mathematics Education, Problem-Solving Skill, System of Equations with Two Unknowns, Verification

\section{Introduction}

Today, most mathematical education programmes, which are not too complicated, require students to know how to use mathematical models (mathematical formulas, algebraic equations, figures) to describe situations. Furthermore, teachers at high school are calling on students to develop a mathematical model to explain the situation and to provide solutions to mathematical problems posed by the existing model. Next, the answer will be implemented and presented, the solution will be evaluated, and the value of the solution will be reflected. The ability to verify is, in particular, one of the needs of specific learning skills for each level, and students must exhibit the mathematics in real contexts and see the correctness of the solution and be familiar with it.

Education in mathematics also emphasizes the integration of teaching mathematics and practice. This trend calls for more modelling and testing capacity, evaluating solutions and results in comparison with reality. It is, however, known that comparing the results to respond to real-world problems plays a vital role in the process of solving problems through modelling, after resolving mathematical problems. In other words, in solving mathematical problems, the checking results activity does no longer end in the verification step. So what is the next verification going to be to solve pseudo-real problems? How can students verify?

A general method for resolving mathematical problems, such as analyzing the problem, finding a solution strategy, proposing the solution and checking the resolution, has been suggested by the famous educator, Polya (cited by $\mathrm{N}$. P. Loc [9]). In the final step, the activity is carried out, and the requirements and the questions are addressed as follows: a review of deduction activities; assessment of formulas used; verification of calculation; check of problems results; Can the solver answer the questions raised? Is the solution reasonable? What solution can be applied to the method? What can students learn to cope with the problem? Can such problem be solved? Can the students generalize the problem? Can the students broaden the problem? 
Meanwhile, the author, H. I. Bukari [2] teaches students in groups a procedure to resolve word problems involving linear equations.

1. Read the matter carefully and determine (unknown) what is necessary.

2. To show this unknown, select a variable.

3. Think of an equation plan. Think of a project.

4. To address the resulting equation, use equation properties.

5. Verify the answer.

In step 5, the writer also mentioned verifying the answer to a given problem. The author considers this step vital because it helps students to confirm that the solution method or strategy is correct, such as diagrams, formulas and patterns in finding solutions to a given problem. In some cases, the presented way is not accurate for the question. The author suggests that the teacher should have students provide additional methods until one of them is suitable for giving a proper solution to the mathematical problem. The Ghana Education Service should, therefore, give mathematical teachers in-service training on how to use problem-based learning methods, and mathematics teachers should also integrate problem-based learning in students. If students use this process, the teachers can use cognitive, metacognitive and other strategies to deal with problems in the study of M. G. Gurat [6].

Similarly, the authors, S. Sumirattana et al. [17] also conceived of a 5-step process concerning the real-world problems: a clear definition of the problem, an assessment of the problem situation, plans for solving the problem, implementation of the procedure and a more suitably developed plan, analysis and evaluation of the results achieved and communication of the results. To assess accuracy and relevance in the last step, the author proposes that students share information with others through writing or speaking.

Results of the research of L. E. Pascual \& A. B. San Pedro [14] showed that most students demonstrated a reasonable degree of skill in problem-solving. It was also revealed that those who performed well were good at solving the problem. In the process of resolving real-world math problems, participants did not typically consider the answer verification phase important. Participants had the most common issues: language maladaptation and lack of awareness of the context of the problem. The researchers advocate similar research in a variety of other settings and locations and, if the findings of this study comply, the new curriculum for mathematical education after high schools may need to be restructured.

The investigation of D. Fisher, Y. S. Kusumah \& J. A. Dahlan [8] aimed at determining the ability and the applications of students in linear equations to reason mathematically in systems. The population from one of the junior high schools in Bandung took part in this study with a sample of 32 eighth grade students. The research instrument was used for mathematical reasoning experiments. The research method used was a qualitative research design. Through data reduction, data submission and conclusion drawing, data were analyzed. The numerical reasoning of junior high school students remained low, based on the results of the research. Students were also assessed for verifying and problem-solving at a low standard.

The writer, N. D. Nam [13] presents the application process of modelling for the teaching of mathematics at secondary schools in mathematical instruction. The paper clarified that students had a greater understanding of scientific and practical issues through modelling activities. Nevertheless, one of the obstacles of the modelling process of students is the problem of comparison and model verifying in practice. Most students have no habit of actually taking into account the significance of the problem. Alternatively, only the modelling process is taught by this paper, and the challenge of aggregating results is not clear. The method of verifying and comparing results is also not mentioned.

F. Chalancon, S. Coppe, N. Pascal [3] conducted a study in response to the question: "How is calculated the verification process of teaching equations, inequalities and the operations of expressions with unknowns in classes 8 and 10?". The process is always linked with the understanding of the related concepts. The paper highlighted several factors, namely definitions of "verification" in problem-solving situations, forms of verification (both internally and externally), "private" characteristics of the verification concept, and teaching contracts related to the subjects. The theoretical tool for the implementation of this topic was used. In particular, students believe that the teacher is solely responsible and accountable for the results controlled, corrected and validated.

M. Saboya, N. Bednarz, F. Hitt [16] presented the theoretical foundation for conducting a study to develop teaching situations for secondary school students to create the ability to control in mathematics. These theoretical elements are also useful for our subject. The article also clarifies the control elements. The paper states that numerous studies confirm that mathematics focuses on verification and control, but that it isn't always presented in the students ' work.

Y. Matheron [11] provides related factors such as the verification and control concept, the verification process, the relationship of the controlled object between the public and private sector and the system of education aid. Besides, the thesis utilized experiments to validate the following research hypotheses:

H1: Control technology is used "privately" in the home teaching support system, which relates to the control technology used in the conventional school system.

$\mathrm{H} 2$ : The control technique used by high school students is closely connected to their position in real life or their teaching institutions. 
H3: The control technique used in the supporting teaching system in the case of "good" students extends the relationship established in the teaching system in the classroom; both components are articulated.

These works prove that "verification" is no auxiliary object, which many people frequently overlook, in problems solving situations. Instead, it is a rich subject, and it is an essential part of mathematics teaching.

In Vietnam's Mathematics Curriculum in 2018 [12], educators set goals associated with the formation and development of mathematical competencies with the required requirements such as: raising and answering questions when arguing and solving problems; using reasoning, inductive and deductive methods to understand different ways of solving problems; setting up a mathematical model to describe the situation, thereby offering solutions to solve mathematical problems posed in the established model; implementing and presenting a problem-solving solution and evaluating the implemented solution, reflecting the value of the resolution, generalizing it to the same problem; using mathematical tools and tools in studying, discovering and solving mathematical problems. In regards to the concept of verification and control, students are asked to explain the correctness of the solution (whether the conclusions from the calculations are meaningful, practical or not). In particular, students need to identify approaches to simplify, adjust actual requirements (approximations, add assumptions, generalization) to address the problems.

Furthermore, these two subjects are closely related to the issue of critical thinking, allowing the students to get in touch with a problem which they can evaluate whether the results are correct or wrong without the involvement of teachers.

\section{Theoretical Framework}

\subsection{Verification}

Following on from S. Coppé (quoted from F. Chalancon [3]), a student has identified some of the results or the final results in a problem-solving situation. The student asks whether this result is valid, known as verification, so all arguments or actions will be taken by the students to reduce the uncertainty of the consequences if they need to. The significance of this verification is to increase certainty and possibly confirm the results or create a more considerable suspicion, even lead to a correction.

In a specific situation, therefore, a verification occurs when the individual (the person dealing with the problem) achieves or has to see an inevitable result (not forcibly the ultimate consequence). This verification is aimed at improving and reducing the subject 's confidence in this result, rather than making a claim or rejection of the achievement possible, meaning that the accuracy of the result is not guaranteed when the verification is successful.

S. Coppé (quoted from F. Chalancon [3]) distinguished two types of verification. The first type is called the internal kind of verification and based on mathematical knowledge and skills. For example, replace the solution found in the given equation; check to see if the product of two solutions of the quadratic equation just solved has the formula. Occasionally, as a consequence of time, the subject only verifies one of the two systems (sum or product of two solutions) to increase confidence in the result of the resolution but does not retest the entire transformation steps. The second type of verification is external. This verification does not rely on mathematical knowledge but is based primarily on personal experience. For example, the solution of an equation is not too complex numbers.

From this description of Coppé, it is considered that verification based on the implicit rules of teaching contracts for a knowledge object belongs to the type mentioned above of peripheral verifying. S. Coppé simultaneously suggested some verification methods as follows:

(1) Verifying the solution steps.

(2) Verifying conditions.

(3) Verifying by testing in some cases.

(4) Verifying by collating with another issue.

(5) Verifying based on some expertise that is not influenced by mathematics or in other words, depending on contract rules.

(6) Verifying based on some real-world knowledge.

(7) Verifying based on the memory of knowledge and exercises taught by teachers.

(8) Verifying by similar collation with a certainty.

Moreover, the author also believes that there will be a particular verification technique depending on every specific mathematical situation.

\subsection{Control}

Control has a broader scope than verification; it involves inspection. Control is regarded as an additional range compared to verification of legalizing answers. Verification leads to the possibility, while the control takes into account the right. The verification is more about 'possibility' (maybe actuality) than about truth (correctness).

M. Saboya, N. Bednarz, F. Hitt [16] further clarified the following characteristics of the control concept about the verification concept. "Students must be able to verify their results, assess coherence, validity, process rigidity and the ability to monitor their solution by assessing and verifying before a mathematical product. These actions show that the control in mathematical activities taken by students reflects the development of students' mathematical rationality".

Control does not only appear at the beginning as a sense of results or at the final resolution step as a solution check, 
but it is also present at all stages of the resolution process in establishing an image of the situation, making decisions, assessing the appropriateness of the task goals. The verification is in favour of explaining the results achieved. It appears as a validation of the outcome, aiming to gain certainty or doubt and entails correction.

"Control is a reversal, revisiting the situation to choose the right and most effective strategy for saving time". "When problems are resolved, controlling activities also occur when students face dead ends. When they are facing an obstacle, at this moment, students need to mobilize knowledge and conduct control to overcome barriers".

M. Saboya, N. Bednarz, F. Hitt [16] has proposed the following reference framework, which provides a foundation for developing the control capacity of students in educational situations. Six elements of the control concept cover this reference framework, of which inspection is only one component.

(1) Anticipation:

It is possible to first set a reasonable condition of the result before achieving the result.

(2) Verification and validation:

- They carry out verification in turn, frequently throughout task performance. The results achieved can result in the task being returned, a method change or a calculation review.

- The students implement the process of legalizing an inference, confirming the correctness of a statement, a process, a calculation.

(3) Reflection:

Making the meaning appear; the inner meaning of the concept is being processed. Pause to think; look back at the task.

\section{(4) Discernment and clear choice:}

Predicting many possible solutions. Making a wise choice between strategies is possible by identifying which is most effective; without numerous errors.

(5) The idea of meta-knowledge:

Students are mobilizing knowledge of the super knowledge category. They are associated with decision making by the use of experience in a given task (and associated with the different meanings and forms of expression of this knowledge).

(6) Perception of errors, understanding of contradictions. Ability to overcome obstacles:

Recognizing inconsistencies and unexpected results does not make sense; they can overcome these conflicts.

\subsection{Pseudo-real Problems}

This section is presented by the author, L. V. Tien [20], Y. Chevallard and L. Coulange distinguished three different concepts: real-world problems, pseudo-real problems and mathematical problems. According to these authors, the real-world problem is outside the domain of mathematics, the pseudo-real problem is in the pseudo-real area, and the mathematical problems belong to the range of mathematics.

A pseudo-real problem is a problem where facts, variables, requirements, questions, relationships are not elements of reality but are simulations (or reflection) of this practice. In other words, there is a difference between a real-world problem and a pseudo-real problem. This difference is often a consequence of the constraints of the teaching system. For example, the numerical value of the data given in a problem is usually chosen so that the calculation is not too complicated; the result ("answer") is "nicer". Mathematical problems are problems in which mathematical languages and symbols contain facts, variables, requirements, questions, relationships. It is a challenge to identify real-world problems in the above sense in the current high school in Vietnam; most of them are pseudo-real or mathematical problems.

The authors are involved in the scope of this study, the situation of resolving pseudo-real problems in the above sense, and, because of individual requirements, research must, of course, state the elements of the real-world problem. They study examination objects, inspections and modelling characteristics.

\subsection{Conclusion, Evaluation and Validation Phases}

In the context of solving problems, C. Margolinas [10] proposed the concepts, namely, conclusion phase, evaluation phase and validation phase. The author states that the conclusion phase has the following two characteristics. It is at the end of the student's problem-solving process. In this phase, students receive information about the validity of the work that they have just done; that is, the results of solving their problems. In the assessment phase, it is the teacher who assesses in a final judgment the validity of the student's work. Meanwhile, in the validation phase, students decide on the validity of their work; that is, they evaluate the results of solving their problems. These phases are explicitly designed in the scenario of the study.

\subsection{The System of Equations with Two Unknowns in Vietnamese Textbooks}

Vietnam's 9th mathematics textbook [4] has introduced the process of solving problems by creating a system of equations with two unknowns:

Step 1. Setting up the system of equations:

- Selecting two unknowns and setting appropriate conditions for them.

- Representing unknown quantities through unknowns and known quantities.

- Preparing two equations to describe the relationship 
between the quantities.

Step 2. Solving the above two equations.

Step 3. Answering: check that the solutions of the system of equations; which solution is appropriate for the problem and its conclusions.

This institution also suggests that students have become familiar with how to cope with problems by first and one order equations. Hence, when moving into this lesson, students are no longer surprised by the solution method. The only difference is that selecting two unknowns instead of previously selecting only one unknown. As a result, the teacher has the opportunity to focus on analyzing the relationships between the quantities in the problem so that students can choose an appropriate method and form a system of equations with two unknowns. In step 3, educators are required to verify the solution of the problem; however, no detailed instructions have been provided for this activity.

Moreover, all of the problems in this section mostly satisfy the initial conditions, making the comparison of students more formal and meaningless. In the proposed solutions, it is found that there is always a step that sets the requirement for unknowns. This step appears, however, to be only a formality because the problem information is still selected so that the system solution meets the unknown conditions. This explanation is also part of the reason that hinders the ability to verify in students.

\section{Objectives of the Study}

(1) Observing whether students perform the verification or not when they address the pseudo-real problems involved with the system of equations with two unknowns? If yes, how did students do it?

(2) Considering the appearance of some elements of the control: initial anticipation, discernment and clear choice, perception of errors, understanding of contradictions.

(3) Changing the personal relationship of students by building situations and scenarios so that students are aware of the need to verify and control.

\section{Materials and Methods}

\subsection{Participants}

Experiments were conducted on 91 students of grade 10 of Thanh Da High School with average level - relatively in the individual working phase of the experiment cards (4 problems) and conducted in a class of 45 students divided into four groups in control discussion related to the problem 4. The students were given experiment cards and draft paper. Experimental cards and scratch paper were collected for analysis. Simultaneously, it was helpful to observe and analyze the changes of students when solving situations through assignments, scrap paper collected from students, audio files and videos recording the process of debate and control of groups.

\subsection{Instruments}

Four pseudo-real problems are tools used for impact, designed with the types of issues to be associated with the solution of the equations system with two unknowns.

Problem 1: A container of $300 \mathrm{~g}$ of salt solution has a concentration of $2 \%$. Ask how many g of water or salt is added to get a $4 \%$ solution of salt solution.

Problem 2: In the Chemistry lab, the teacher gives An and Binh a $200 \mathrm{~g}$ vial of the sulfuric acid solution with a concentration of $98 \%$. The teacher wants them to create an acid solution with a level of $50 \%$. Calculate the number of $\mathrm{g}$ acids or acids and water they need to make the solution.

Problem 3: Linh has one bill of VND 100,000. For a convenient shopping, she has changed to 30 banknotes of VND 1,000 and VND 5,000. Calculate the number of sheets each she has redeemed.

Problem 4: Thao and her mother plan to travel to Hoi An and Da Nang City Center on the occasion of the Lunar New Year and rent a hotel for six days (except for the time of moving and waiting for check-in between two locations) and stay at a 3-star hotel. After deducting other expenses, they are expected to have VND 5,500,000 to rent the hotel. Knowing that the cost of renting the cheapest 3-star hotel per day in Hoi An is VND 600,000 and in Da Nang is VND $1,000,000$. Please calculate with such amount; they will be able to rent a hotel room in each location for how long?

\section{Pre-analysis of four given problems}

(1) Problem 1 and 2 are unfamiliar problems that show. In problem 1, the quantity to be searched and the other amount not to be found explicitly appear in the question and the problem of two quantities. If the search is not expressly stated in the question, the researchers want to investigate whether the student has the "anticipation" element. Problem 1 contains the search quantity for (salt) and the search quantity for (water). Nonetheless, in the questioning method in problem 1 , we intentionally put the quantity that we do not need to find (water) before the quantity we want to see (salt). "Ask how much water or salt to get a container $4 \%$ salt solution. " to investigate whether students appear the element of "feeling" or not, it is governed by an implicit rule of contract "Only the quantity to be found appears explicitly in the question". In this exercise, it is somewhat similar to problem 1; the quantity to be sought (water) is not specified in the question. Still, the dimension of "feeling" appears simultaneously raised in parallel with the quantity of acid (quantity not found in problem 2). It also creates favourable conditions for studying whether or not there is a "discernment, wise choice" factor in students by choosing to add water or adding both water and acid to the new solution.

Students are expected to be able to answer in two approaches: 
(1) Students respond yes and pick a pair of numbers that meet the requirements of the problem. Perhaps the student is going to give many couples of satisfying needs.

(2) Students reply no since there are insufficient data or many pairs of numbers are satisfied. The approach to the preceding first quadratic equation has the potential to help most students realize that there will be many solutions to this problem. Problem 3 is a mathematical form that does not appear in textbooks but appears more or less in grade 10 exam questions of schools. The issue has the result removed from the original condition. Through the problem, we can investigate whether students perform the test results after solving with the initial conditions and whether students perform the test compared to reality or more general than them. Which verification strategy to use?. For this problem 3, students can resolve by putting a one-unknown equation or two-equation system. Results that students may receive to conclude that money cannot be exchanged upon request.

(3) Problem 4 is a problem that breaks the contract rule "The solutions found do not conflict with reality" so that we can consider the individual's views on the test object. Specifically, we want to investigate whether after checking the results on the condition that the student will perform the test with the actual results at the beginning. This problem satisfies the initial requirement but is not reasonable in practice. In this problem 4, the data is not a beautiful integer, meaning that the mother and child in each hotel are not round enough to create favourable conditions to appear the strategy to test the problem results with reality. This problem is to contradict the findings of the mathematical one, and it creates the conditions for students to investigate the outcomes and to examine if the students conduct a test in real life or if the results are stopped in comparison with the initial conditions. It is only at the test stage that this test stops compared with which is the first stage to test the initial conditions or to test with reality how they argue about establishing the initial conditions of problem 2 and can see that they say about checking the results of this problem.

Table 1. Students can use verification and control ways

\begin{tabular}{|c|l|}
\hline Ways & \multicolumn{1}{c|}{ Contents } \\
\hline 1 & Only compare results found with initial conditions \\
\hline 2 & Only compare results found with reality \\
\hline 3 & $\begin{array}{l}\text { Compare the results obtained with the initial conditions } \\
\text { and with the actual conditions }\end{array}$ \\
\hline 4 & $\begin{array}{l}\text { Reconcile results with experience (with contract rules). } \\
\text { Specifically, the following contract rules: } \\
\text { "The solutions found do not conflict with reality." } \\
\text { "The system of equations always has a unique solution, } \\
\text { and the data are beautiful whole numbers." }\end{array}$ \\
\hline 5 & Verify and control all the solutions of the problem again. \\
\hline
\end{tabular}

Some verification and control methods can be employed by students in the process of solving four given problems (see Table 1)

\subsection{Scenario Design}

The scenario is divided into two phases.

(1) Phase 1: Personal work (45 minutes).

The objective of phase 1: Creating conditions for each student to express an independent view from which there is an objective result of the student's relationship with the test subject and some components of the control object.

- The teacher distributes learning cards and draft papers to each student solving problems $1,2,3$ and 4 .

- Then the teacher collects the work and draft paper of the students (not informing the collection of draft paper for the previous students to create conditions for students to present on the draft paper naturally).

- The teacher can interview students if needed.

The researchers decided to work for each student individually in phase 1 to independently express their opinions so that they can assess the relationship between the student and the verification subject and a few other components of the control object.

\section{(2) Phase 2: three steps (30 minutes)}

Still using one of the four problems in phase 1, namely problem 4.

\section{(i) Step 1: Teamwork (15 minutes)}

The objective of the group working step: Creating conditions for students to debate, thereby helping some students discover the problem, contributing to changing the personal relationship of students with the verification subject in problem 4.

- The teacher divides the class into four groups and announces the group.

- The task of each group is to draft a standard solution for problem four on A2 paper.

- The teacher gives groups an A2 sheet with their group 's consent and a draft paper.

- Students conduct group work.

- The teacher assigns observers to record and record videos of the working process of groups, which should create conditions for students to work in groups naturally.

\section{(ii) Step 2: Debate time (15 minutes)}

This step is aimed at creating conditions for students to be aware of the need for practical analysis of the problem 4 , and this gives a specific amount of VND 5500,000 to rent a hotel in Da Nang and Hoi An. It will provide conditions for students to consider how to respond to the number of days at each location so that the math solution will provide sufficient money or not. 
Arguing about problem 4

- The teacher asks groups to hang problem-solving problem 4 on A2 paper on the board (at the same time).

- The groups post problem 4 on A2 on the board and discuss this as a whole class.

- Groups debate agreeing on results for problem 4.

- If after controlling the entire level, students find out that they need to check the problem results compared to reality, the script will end. If not, skip stepping 3.

(iii) Step 3: Time to control problem 4 (5 minutes)

- The teacher gives each group 2 tables of regulations on the stay of two 3-star hotels in Da Nang and Hoi An.

Table of regulations on the stay of a 3-star hotel in Da
Nang (see Figure 1).

\section{Length of stay}

Check-in time is after $2 \mathrm{pm}$ and check-out time is noon.

Late check-out until 3 pm (in case of availability): the hotel will charge $30 \%$ of the room rate.

Late check out until 6 pm (in case of availability): the hotel will charge $50 \%$ of the room rate.

Late check-out after 6 pm: the hotel will charge $100 \%$ of the room rate per night according to the contract price.

Note

Book the holidays in the year surcharges VND 300,000 / room/day; $100 \%$ prepayment is required and no refund, no cancellation.

Figure 1. Regulations on the length of stay of a 3-star hotel in Da Nang

Table of regulations on the stay of a 3-star hotel in Hoi An (see Figure 2).

\section{* CHECK-IN OR CHECK-OUT NHẬN/TRẢ PHÒNG}

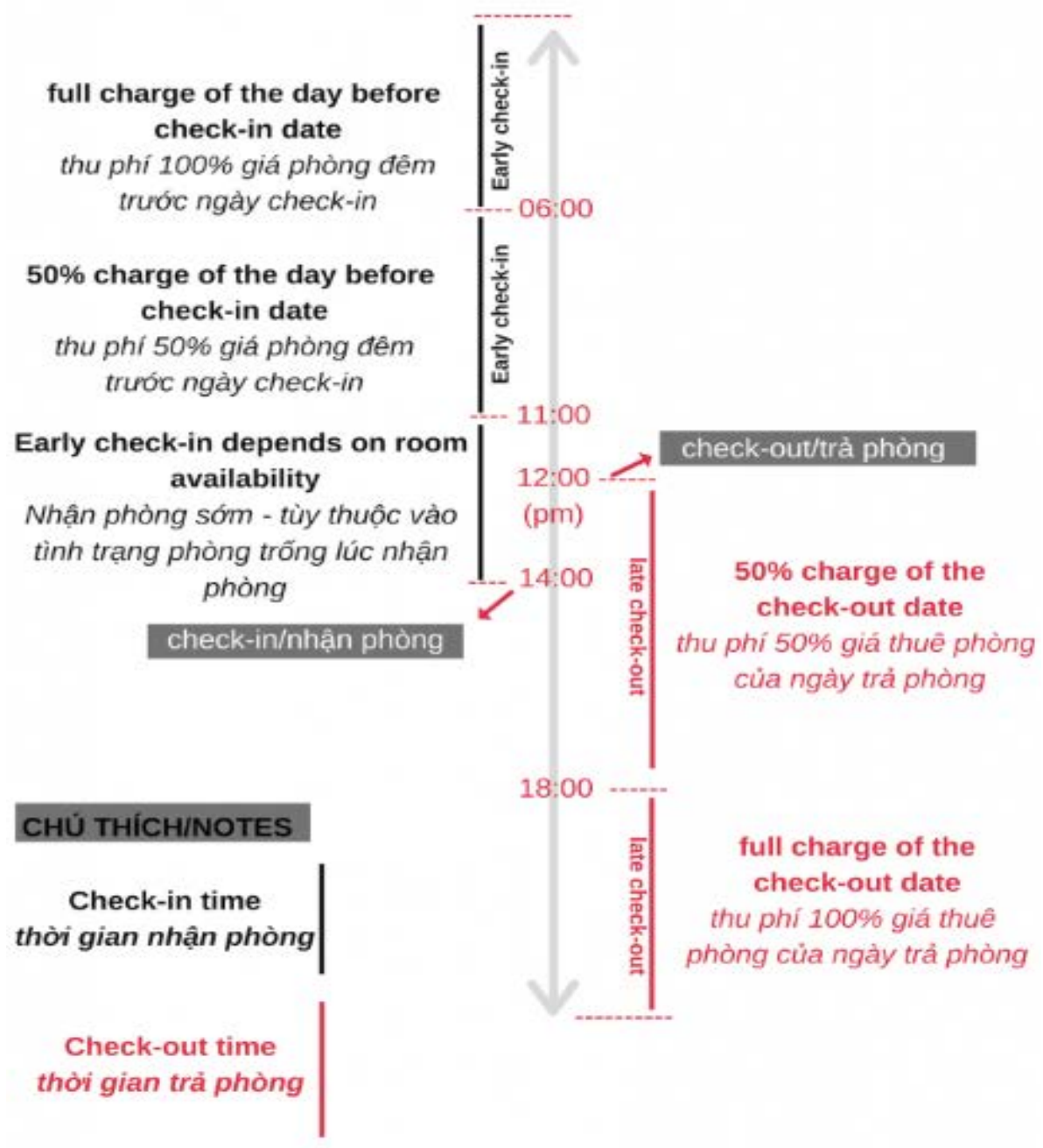

Figure 2. Regulations on the length of stay of a 3-star hotel in Hoi An 
Then the teacher asks the groups if they have any thoughts or comments about the solution of problem 4 ?

Note: The teacher sends the cameraman to the class debate phase.

\subsection{Data Analysis}

The data collected included empirical papers, draft paper, video of a work process, video of discussions and stages of control. The data were quantitatively analyzed to determine the number and proportion of students using verification and control to address the problems. Instead, qualitative analysis was used primarily for clarifying student work, audio files and debate in groups. Also, some students were interviewed to understand better how they verified and controlled their responses.

In this study, the researchers did not use a model consisting of an experimental class and a control class like other researchers. Usually, such studies were associated with pre-test and post-test. However, this research was considered as a case study because only one group was selected. A pedagogical script was designed to be suitable for research purposes. In particular, the stages of the individual intentional scenario included examining students' ability to verify and control the presented results as well as promoting their awareness in recognizing the importance of both activities. It was for this reason that data was not analyzed much quantitatively but instead of focusing on qualitative analysis. An attempt was made to clarify and explain student work as well as their verbal statements.

\section{Results and Discussion}

\subsection{Results of Stage 1 (Personal work on four given problems)}

Table 2. Statistics of the number of students with or without the "anticipation" element when solving problem 1

\begin{tabular}{|c|c|c|}
\hline $\begin{array}{c}\text { The emergence of an } \\
\text { "anticipation" element }\end{array}$ & Amount & Percentage \\
\hline Yes & 21 & $23.08 \%$ \\
\hline No & 70 & $76.92 \%$ \\
\hline
\end{tabular}

Table 2 showed that 21 students felt perceived when solving problem 1 . Of these, 14 of them had incorrect answers, but there was an "anticipation" element, so they still belonged to this group. Besides, there were quite a few students who ultimately did not have anticipation in problem 1 . The aspect of "anticipation" appeared not only in one part of the student but also in specific manifestations of implications and conclusions.

According to Table 3, 12 students felt perceived that when solving problem 2 lower than problem 1 . The appearance of the "anticipation" element was also shown by some excerpts of the individual work of some students. They did not complete their work but still had a feeling when solving problem 2. The number of students remaining 79 students did not appear the "anticipation" element in the test; most of them were interviewed apart from the answers. "I am not good at Chemistry," a group of students asked, "the question of how much g or more acid and water is needed?". This answer proved that the existence of a contract rule "the quantity to be found typically appeared explicitly in the question" and therefore, what questions the student put unknown was that quantity.

Table 3. Statistics of the number of students with or without the "anticipation" element when solving problem 2

\begin{tabular}{|c|c|c|}
\hline $\begin{array}{c}\text { The emergence of an } \\
\text { "anticipation" element }\end{array}$ & Amount & Percentage \\
\hline Yes & 12 & $13.2 \%$ \\
\hline No & 79 & $86.8 \%$ \\
\hline
\end{tabular}

When collecting study papers, teachers interviewed some students "Where do you encounter difficulties in problems 1 and 2?" and received many answers with the same content "Ask how much g salt or water why? And how many grams of acid or acid and water?" These answers meant that students encountered problems when the quantity to be sought did not appear explicitly in the question as familiar problems that they met in textbooks, and the "anticipation" factor did not appear in these students.

A large proportion of students left their homework empty or gave inappropriate solutions. From that, it was necessary to pose a question: "Is it possible to have the "anticipation" element in students when adjusting the question in the problem into an open question? Affordable question factors open or close was one of the factors affecting the "anticipation" in students.

Based on the data of Table 4, 71 students used "Only compare results found with initial conditions". However, the contract rule "Equation system has always a unique solution, and the data are beautiful integral data", and the rounding law was affected, which meant that they did not respond in the right method. Moreover, the requirement that the number of student bills was more significant than zero was not reasonable; thus, the exact solution was not given. So what are the consequences for hiding from a student's standpoint? How did they make the hidden condition accurate? As many students falsely circumstantiated, it was also incorrect to verify the results under the initial conditions. Furthermore, some students controlled the results by retrying the replies $x$ and $y$ to check whether or not the sum produced VND 100,000 to see if $x$ and $y$ were equation solutions. Another group of students did not review the results consciously, even though their requirements for the problem were determined. 
Table 4. Statistics of results using students' verification and control techniques when solving problem 3

\begin{tabular}{|c|l|c|c|}
\hline Ways & \multicolumn{1}{|c|}{ Contents } & Amount & Percentage \\
\hline 1 & $\begin{array}{l}\text { Only compare results found } \\
\text { with initial conditions }\end{array}$ & 71 & $62.3 \%$ \\
\hline 2 & $\begin{array}{l}\text { Only compare results found } \\
\text { with reality }\end{array}$ & 0 & $0 \%$ \\
\hline 3 & $\begin{array}{l}\text { Compare the results obtained } \\
\text { with the initial conditions and } \\
\text { with the actual conditions }\end{array}$ & 0 & $0 \%$ \\
\hline $\begin{array}{l}\text { Reconcile results with } \\
\text { experience (with contract } \\
\text { rules). Specifically, the } \\
\text { following contract rules: } \\
\text { "The solutions found do not } \\
\text { conflict with reality." } \\
\text { "The system of equations } \\
\text { always has a unique solution, } \\
\text { and the data are beautiful } \\
\text { whole numbers." }\end{array}$ & $\begin{array}{l}\text { Verify and control all the } \\
\text { solutions of the problem } \\
\text { again. }\end{array}$ & 17 & $26.8 \%$ \\
\hline
\end{tabular}

Nevertheless, when dealing with problem 3, most students did not feel difficult but felt too familiar, but until the conclusion of the final challenge, most of them were confused. Most students implemented the verification strategy "Only compare the results found with the initial conditions". Conversely, there were only eight students among them with the correct answer, a large proportion of students used the verification strategy "Collate results with experience (with contract rules)". The period was affected by the rounding rule, and the specific contracting states were "The solutions found will satisfy the problem conditions", "The system of equations typically has a unique solution, and the data are beautiful integers". Accordingly, the learners did not come up with the correct solution. It was worth mentioning here that when solving mathematical problem 3, many students expressed the question "Why is the number of bills odd" or "teacher, the wrong topic", but the majority of students were still determined to conclude. Alternatively, the answer was a bit illogical, "12.5 banknotes of VND 1,000 and 17.5 banknotes of VND 5,000." This reply was able to explain that some contract rules also bound the verification of the results of a problem.

The information from Table 5 indicated that most students (accounting for 62.3\%) deployed the verification strategy to test results with initial conditions. However, they still were affected by the contract rules and rounding rules such as problem 3 . There was not any student using the approach "Compare the results found with the initial conditions and with the reality". A part of students set the conditions $x, y \in N^{*}$. Furthermore, some other students were still influenced by the rounding rule. Meanwhile, only seven students performed verification and control for the entire solution of the given problem.
Table 5. Statistics of results using students' verification and control techniques when solving problem 4

\begin{tabular}{|c|l|c|c|}
\hline Ways & \multicolumn{1}{|c|}{ Contents } & Amount & Percentage \\
\hline 1 & $\begin{array}{l}\text { Only compare results found } \\
\text { with initial conditions }\end{array}$ & 71 & $62.3 \%$ \\
\hline 2 & $\begin{array}{l}\text { Only compare results found } \\
\text { with reality }\end{array}$ & 0 & $0 \%$ \\
\hline 3 & $\begin{array}{l}\text { Compare the results obtained } \\
\text { with the initial conditions and } \\
\text { with the actual conditions }\end{array}$ & 0 & $0 \%$ \\
\hline & $\begin{array}{l}\text { Reconcile results with } \\
\text { experience (with contract } \\
\text { rules) Specifically, the } \\
\text { following contract rules: }\end{array}$ & $\begin{array}{l}\text { "The solutions found do not } \\
\text { conflict with reality." } \\
\text { "The system of equations } \\
\text { always has a unique solution, } \\
\text { and the data are beautiful } \\
\text { whole numbers." }\end{array}$ & 13 \\
\hline 5 & $\begin{array}{l}\text { Verify and control all the } \\
\text { solutions of the problem } \\
\text { again. }\end{array}$ & 7 & $7.7 \%$ \\
\hline
\end{tabular}

\subsection{Results of Stage 2 (debate time about problem 4)}

Phase 1: Debating how to set initial conditions.

After the debate, all groups agreed to set the conditions for the problem 4 " $0<x, y<6$ ". When interviewed by the teacher, why did students set such a state but did not fix the term " $x, y \in N^{*}$ ", then the teacher received the answer "Yes, they do not have to hire a hotel, but they can hire more hours". Another student answered, "There are a day and a half, so there are still odd days for you". As such, it was understandable that limited placement partly depended on the personal experience of each student.

Phase 2: When the results of the problem were addressed $x=12.5 ; y=4.75$, all four groups did not doubt the amount to pay to the hotel when staying in Hoi An 6 hours a day and staying in Da Nang 4 days 18 hours. For this reason, this debate stage 2 did not take place.

The teacher gave each group 2 sheets of information on 3-star hotel residence rules in Da Nang and 3-star hotels in Hoi An; the teacher did not give any more explanations to create the conditions for discussions groups to comment on problem 4. Students managed two of these two hotels' regulations. In five minutes, the teacher asked the groups to rethink the solution of their group. Three groups succeeded after the control phase, except for group 3 who had not yet commented, the remaining three groups said that the mother and child could not afford to pay if staying at a hotel with some days as calculated.

The teacher interviewed several members of the groups and received some answers. Student 1: "I think the mother and her son could not pay if they stay with the above number of days as if with such regulations, in Hoi An, they had to pay VND 600,000 plus 50\% of a day rent for 6 for an extra hour. The total is VND 900,000 and the equivalent for four days in Da Nang is VND 4,000,000 plus $100 \%$ of the one-day rent is VND 5,000,000. So the total is VND 
$5,900,000$. As a result, they cannot afford to pay”.

Student 2: "They could not allow themselves to remain the number of days that were already addressed due to additional time, and they attended the ceremony to pay extra for their holidays".

Student 3: "Mother and her son did not take care of surcharges, so 5.5 million was not sufficient to cover the previous days".

Another student was quite vague but said, "This result is not correct, and the hotel regulations seem unreasonable".

In the working group, the verification strategies in most groups "re-check the entire solution" and "verify the equations system with initial conditions". The groups were quite active, and three different groups replied correctly after the control phase for problem 4 . The verifying and controlling the performance results made students more aware of the answer to the question. The commenting of the solutions employing the speech made sense and was also mentioned in the research of S. Sumirattana et al. [17].

\section{Conclusions and Suggestions}

In problems 1 and 2, the "anticipation" element in several students appeared during the individual work phase. Besides problems 3 and 4, the results of the verification were not scrutinized by all students. In practice, most students only tested or checked the results with initial conditions for the solution of the equation system. At the same time, this inspection was governed by the rules of the contractual arrangement. Besides, some students had difficulties in understanding the content of given word problems, similar to the research of R. F. Zahrah and W. D. Febriani [21]. In the group work phase, most of the team members only debated on how to set the conditions for the two unknowns $x, y$ corresponding to the number of days in Hoi An hotel and the number of days in Da Nang hotel, about the results of the problem were almost not discussed. This information reflected the fact that students did not consciously verify the problem results with the previous practice.

In the groups' control phase, the results of problem 4, which students were not exposed previously, were reconsidered after reading the regulations for two 3-star hotels in Hoi An and Da Nang. The results of the examination showed that the students realized that the results of the control phase reality problems or, in other words, the procedure for creating a situation or scenario were essential and necessary for verification and control.

Experimental results revealed that several students had the appearance of the "anticipation" element of the control object that the researchers chose. In the majority of students, the student's relationship with the purpose of verification was only shown by the "result control" strategy, with students having no way to see the results.
Simultaneously, student verification was dominated mainly by contract rules and several other mathematical rules. The authors designed the control phase after group debate in the script part experiment to help students compare the results of the problem with the actual outcome and gradually understand the importance of verifying and consciously controlling the result of the problem. Overall, the researchers achieved their original research goals. In particular, a small number of students verified and monitored before the final step of the math problem; some fundamental elements of the control also appeared. The ultimate goal was to make students realize the importance of these two skills in solving problems associated with the practice.

Additionally, empirical findings draw some critical implications and suggestions for students and teachers. The research of F. Gull and S. Shehzad [5] also demonstrates the positive effect of collaborative learning activities on the academic achievements of students in education. In this study, each student could work and study to learn, in many ways, with other students, as well as cooperation skills. Each student was able also to express their views and thoughts during a discussion and could listen to the opinions of each group member. At the same time, each student could talk, exchange and oppose different ideas, and then select the best solution and designs to best fulfil its tasks. Accordingly, the knowledge received by the students would lead to greater scientific objectivity, less subjectivity and less self-image and the development in each student of critical thinking. It gave shy, quiet students an excellent opportunity to be bolder, to learn how to communicate with friends and how to present ideas from students since all of the students were able to express their views openly. From that point on, they could integrate with the group, became more interested in learning and group activities and had more confidence in themselves. Besides, students also developed mathematical modelling competencies, mentioned in the study of Supriadi [18] because they had been involved in resolving problems associated with everyday life. All the students in the group should, however, be aware that the problems they solve are the problem of the entire group, the task of each member.

Consequently, each member contributed together to the success or failure of the group. All team members shared the results equally. Similarly, J. Hannah \& Kate [7] also addressed the effect of learning approaches on the measurable success of a student concerning the school factors. Furthermore, according to Y. D. Arthur et al. [1], the process of learning mathematics associated with reality also contributed to enhancing students' interest in learning.

Regarding teachers, they enhance their ability to observe students, their knowledge and their teaching experience by organizing student group work and debate. Also, the teachers practise the skills of communication and cooperation with their students. Because there are many 
students in groups, some of them are timid or want to not participate in group activities for some other reason. K. F. Patrick [15] claimed that teachers had an essential role in helping students participate in the primary school to enhance learning and that pedagogy teachers themselves help to develop suitable work practices. As such, the role of the teacher assigned is crucial since if the job is unreasonable, some excellent and smart students can be involved, and the majority of other students can not act or interact. Teachers must also specify and limit the time needed for group discussions, present control findings, facilitate inter-group cross-examination, or the whole class. When students talk and debate, the teacher in charge must listen, observe, propose and support groups when necessary. Also, the process of teaching problems concerning practice requires teachers with an understanding of mathematical modelling and problem-solving [19].

\section{REFERENCES}

[1] Y. D. Arthur, E. K. Owusu, S. Asiedu-Addo \& A. K. Arhin. Connecting Mathematics To Real-Life Problems: A Teaching Quality That Improves Students' Mathematics Interest, IOSR Journal of Research \& Method in Education (IOSR-JRME), Vol.8, No.4, 65-71, 2018.

[2] H. I. Bukari. Using Problem-Based Learning to Enhance Junior High School Students' Understanding and Attitude Towards Linear Equations Word Problems, Journal of Education and Practice, Vol.10, No.3, 126-135, 2019.

[3] F. Chalancon, S. Coppe \& N. Pascal. Verifications in Equations, Inequalities and Elementary Algebra, Petit x., No.59, 23-41, 2002.

[4] P. D. Chinh, T. Than, N. H. Doan, P. G. Duc, T. C. Thanh \& N. D. Thuan. Mathematics 9 ( $2^{\text {nd }}$ ed. $)$, Ho Chi Minh City, Vietnam: Education Publishing House, 2014.

[5] F. Gull \& S. Shehzad. Effects of Cooperative Learning on Students' Academic Achievement, Journal of Education and Learning, Vol.9, No.3, 246-255, 2015.

[6] M. G. Gurat. Mathematical Problem-solving Strategies among Student Teachers, Journal on Efficiency and Responsibility in Education and Science, Vol.11, No.3, 53-64, 2018.

[7] J. Hannah \& Kate. The Influence of Learning Strategies on the Mathematics Achievement of Students as It Relates to School Factors, Journal of Education and Practice, Vol.10, No.13, 52-57, 2019.

[8] D. Fisher, Y. S. Kusumah \& J. A. Dahlan. Junior High School Students' Mathematical Reasoning Ability Analysis in Systems of Linear Equations and Applications, Journal of
Physics: Conference Series, 1315 012044, 2019.

[9] N. P. Loc. Active Learning Activities of Students in Teaching Mathematics: A Monograph on the Basis of Operational Theory, Publisher of Can Tho University, Vietnam, 2016.

[10] C. Margolinas. The Importance of True and False in the Mathematics Class. Wild Thought, Editions, 1993.

[11] Y. Matheron. Control Process in College Mathematics Class. Study of the Conditions and Constraints of Emergence, Master Research in Mathematics Didactics, University of Aix Marseille, France, 2015.

[12] Ministry of Education and Training. Mathematics Education Curriculum, Vietnam, 2018. Retrieved from https://data.moet.gov.vn/index.php/s/LETzPhj5sGGnDii\#p dfviewer.

[13] N. D. Nam. Mathematical Modelling Competencies of High School Students, Scientific Journal of Hanoi University of Education, Vol.60, No.8, 44-52, 2015.

[14] L. E. Pascual \& A. B. San Pedro. Post Secondary Students' Level of Proficiency in Solving Real-World Problems in Mathematics, Journal of Applied Mathematics and Physics, Vol.6, 198-214, 2018.

[15] K. F. Patrick. The Importance of Teacher Role in Cooperative Learning: The Effects of HighStakes Testing on Pedagogical Approaches of Early Career Teacher in Primary Schools, Education 3-13. Vol.46, No.1, 89-101, 2018.

[16] M. Saboya, N. Bednarz \& F. Hitt. Control over Mathematical Activity as A Component of Rationality in Mathematics: Development of A Frame of Reference., Proceedings of Scientific Workshops EMF, 2006.

[17] S. Sumirattana, A. Makanong \& S. Thipkong. Using Realistic Mathematics Education and DAPIC Problem-solving Process to Enhance Secondary School Students' Mathematical Literacy, Kasetsart Journal of Social Sciences, No.38, 307-315, 2017.

[18] Supriadi, D. Suryadi, U. Sumarmo \& C. Rakhmat. Developing Mathematical Modelling Ability Students Elementary School Teacher Education Through Ethno Mathematics-based Contextual Learning, International Journal of Education and Research, Vol.2, No.8, 439-452, 2014

[19] O. D. Temur. Analysis of Prospective Classroom Teachers' Teaching of Mathematical Modelling and Problem-Solving, Eurasia Journal of Mathematics, Science \& Technology Education, Vol.8, No.2, 83-93, 2012.

[20] L. V. Tien. Methods of Teaching Mathematics in High Schools, Ho Chi Minh City University of Education: Publishing House, 2005.

R. F. Zahrah \& W. D. Febriani. A Contextual Problem Based on Local Wisdom Improve The Ability to Solving a Word Problem Mathematics Students of Elementary School, Journal of Elementary Education, Vol.4, No.1, 55-64, 2019. 